\title{
Aerogel and xerogel $\mathrm{WO}_{3} / \mathrm{ZrO}_{2}$ samples for fine chemicals production
}

\author{
Michela Signoretto ${ }^{\mathrm{a}, *}$, Elena Ghedini ${ }^{\mathrm{a}}$, Federica Menegazzo ${ }^{\mathrm{a}}$, Giuseppina Cerrato ${ }^{\mathrm{b}}$, Valentina Crocellà ${ }^{\mathrm{b}}$, \\ Claudia Letizia Bianchi ${ }^{\mathrm{c}}$ \\ ${ }^{a}$ Dept. of Molecular Science and Nanosystems, University Ca' Foscari Venice and Consortium INSTM, RU-Venice, Calle Larga S. Marta 2137, 30123 Venice, Italy \\ ${ }^{\mathrm{b}}$ Dept. of Chemistry \& NIS Centre of Excellence, University of Turin, Via P. Giuria 7, 10125 Turin, Italy \\ ${ }^{\mathrm{c}}$ Dept. of Chemistry, University of Milan, Via Golgi 19, 20133 Milan, Italy
}

\section{A R T I C L E I N F O}

\section{Article history:}

Received 28 May 2012

Received in revised form 17 July 2012

Accepted 9 August 2012

Available online 16 August 2012

\section{Keywords:}

Sol-gel process

Acylation

Tungsten

Zirconium

\begin{abstract}
A B S T R A C T
$\mathrm{WO}_{3} / \mathrm{ZrO}_{2}$ systems were prepared by sol-gel technique using different procedures for the solvent extraction: evaporation in vacuum at room temperature (xerogel) and extraction in supercritical conditions (aerogel). Two reactions of industrial interest were investigated under mild conditions: (i) acylation of veratrole with acetic anhydride; (ii) acylation of anisole with benzoic anhydride. Several techniques were employed in order to study the influence of the synthetic parameters on texture and catalytic activity: $\mathrm{N}_{2}$ physisorption, Fourier transformed-infrared spectroscopy, X-ray photoelectron spectroscopy, temperature programmed reduction and temperature programmed oxidation analyses. The solvent extraction strongly influences metal reducibility, surface area, pores organisation, W/Zr surface density and metallic interactions. The aerogel sample shows the best catalytic results for both conversion and yield. The supercritical extraction plays a central role especially in the recycling: by proper air activation, the aerogel sample attains the complete restoration of the catalytic activity even after three runs.
\end{abstract}

(C) 2012 Elsevier Inc. All rights reserved.

\section{Introduction}

Solid acid catalysts present many advantages if employed instead of traditional liquid $\left(\mathrm{H}_{2} \mathrm{SO}_{4}, \mathrm{HCl}\right.$, etc.) or mineral acid $\left(\mathrm{AlCl}_{3}\right.$, $\mathrm{BF}_{3}$, etc.). In particular, they possess strength and concentration of active sites that can be tailored for particular applications, they present high surface area and adsorption capacity, thermal and chemical stability and above all they are environmentally friendly. Examples of these materials are zeolites [1], heteropoly acids [2], clays and metal oxides. The latest have many applications in organic synthesis either as supports for catalytically active materials or as catalysts themselves. The promotion of metal oxides $\left(\mathrm{Fe}_{2} \mathrm{O}_{3}\right.$, $\mathrm{TiO}_{2}, \mathrm{ZrO}_{2}$, etc.) with sulfated, phosphated and heteropoly-anions leads to solid acids with a wide range of strength [3]. Mixed metal oxides, with two or more components, are of significant scientific and commercial interest [3-5]. In fact these systems exhibit enhanced chemical-physical properties (higher surface area, higher pore volume, superior thermal and chemical stability) and higher catalytic activity than their individual components [6,7].

In this context, $\mathrm{WO}_{3} / \mathrm{ZrO}_{2}$ (hereafter referred to as $\mathrm{ZW}$ ) are very attractive because they display high catalytic activity and stability in processes requiring medium-high acidity or red-ox properties, such as acylation and isomerization reactions [7,8]. Recently the catalytic activity of this system has been evaluated also in catalytic

\footnotetext{
* Corresponding author. Fax: +39 (0)41 2348517.

E-mail address: miky@unive.it (M. Signoretto).
}

processes concerning bio diesel production, as for example in the esterification of fatty acids $[9,10]$. Tungstated zirconia catalysts offer several advantages compared to sulfated zirconia catalysts, such as higher thermal stability, lower deactivation rates, easier regeneration $[11,12]$. The physico-chemical properties of ZW catalysts and, in particular, their acidity strength are strictly correlated to the synthetic procedure and mainly to the relative amount of each oxide. Usually ZW materials are prepared by impregnation of zirconium oxyhydroxide with ammonium metatungstate and subsequent high temperature oxidation or by co-precipitation of the zirconium and tungsten precursors [13,14]. Unfortunately, conventional mixed oxides synthesis techniques do not usually produce homogeneous materials with high surface area. On the contrary, the sol-gel synthesis [15-18] reduces the number of preparation steps and allows the strict control of the physicochemical properties and of the homogeneity of the final materials. In particular, the sol-gel method stabilizes the surface area and the pore volume of the catalysts with respect to the traditional synthetic procedures. Despite these remarkable advantages, only few investigations concerning the sol-gel preparation of ZW systems are present in literature $[15,19,20]$.

This work deals with the synthesis, the characterization and the reactivity of ZW systems obtained via sol-gel. The samples were synthesized by means of different procedures for the solvent extraction: (i) evaporation in vacuum at room temperature (xerogel) and (ii) evaporation in supercritical conditions (aerogel). In order to study the influence of the synthetic parameters on both 
structure and texture of the materials, different characterization techniques were employed: XPS, $\mathrm{N}_{2}$ physisorption, FT-IR spectroscopy, TPR and TPO analyses. The catalytic behaviour of the systems was investigated towards two reactions of industrial interest [21,22]: (i) the acylation of veratrole with acetic anhydride, (ii) the acylation of anisole with benzoic anhydride.

\section{Experimental}

\subsection{Synthesis of catalysts}

The catalysts were synthesized by a one-step sol-gel method [15]. Briefly, the gel was prepared by mixing the metal alcoxides precursors $\mathrm{Zr}\left(\mathrm{OC}_{3} \mathrm{H}_{7}\right)_{4}(18.4 \mathrm{~mL})$ and $\mathrm{W}\left(\mathrm{OC}_{3} \mathrm{H}_{7}\right)_{6}(40 \mathrm{~mL})$ with a mixture of $i-\mathrm{PrOH}$ and water $(60 \mathrm{~mL})$ in presence of $\mathrm{HNO}_{3}(68 \%$, $0.6 \mathrm{~mL}$ ). Two different extraction procedures were used for the solvent extraction. The xerogel sample (termed XZW) sample was obtained by simply removing the solvent from the wet gel under vacuum $\left(10^{-2}\right.$ Torr $)$ at room temperature. The aerogel sample (termed AZW) was prepared by the supercritical elimination of the solvent (i-PrOH) in autoclave at $250^{\circ} \mathrm{C}$ and $4.5 \times 10^{4}$ Torr. The nominal concentration of $\mathrm{WO}_{3}$ was $15 \%$ for all the samples. As reference material, a mere zirconia (AZ) was prepared by a sol-gel approach by the supercritical elimination of the solvent ( $\mathrm{i}-\mathrm{PrOH})$ in autoclave at $250^{\circ} \mathrm{C}$ and $4.5 \times 10^{4}$ Torr. A commercial $\mathrm{WO}_{3}$ oxide (99\% Aldrich) was used as reference too. All samples were calcined in flowing air ( $30 \mathrm{~mL} / \mathrm{min})$ for $3 \mathrm{~h}$ at $800{ }^{\circ} \mathrm{C}$.

A commercial $\beta$-zeolite $(\mathrm{Si} / \mathrm{Al}$ ratio $=108)$ was used as received as reference catalyst.

\subsection{Catalysts characterization}

Surface area and pore volume were obtained from $\mathrm{N}_{2}$ adsorption-desorption isotherms at $-196{ }^{\circ} \mathrm{C}$ (by means of a MICROMERITICS ASAP 2000 Analyser). Prior to $\mathrm{N}_{2}$ physisorption experiments, all samples were outgassed at $110^{\circ} \mathrm{C}$ for $2 \mathrm{~h}$. Mesopores volume was measured as the adsorbed amount of $\mathrm{N}_{2}$ after capillary condensation, while micropores volume was obtained by $t$-plot method. Surface area was calculated using the standard BET equation method and pore size distribution was elaborated using the $\mathrm{BJH}$ method applied to the isotherms adsorption branch [23].

Temperature programmed oxidation (TPO) experiments were carried out in a lab-made equipment. In all experiments $100 \mathrm{mg}$ of sample were introduced in a quartz reactor and flushed by a 5 vol.\% $\mathrm{O}_{2} / \mathrm{He}$ gas mixture $(40 \mathrm{ml} / \mathrm{min})$ at room temperature for $30 \mathrm{~min}$. Then, the temperature was increased from room temperature to $450{ }^{\circ} \mathrm{C}$ with a rate of $10^{\circ} \mathrm{C} / \mathrm{min}$ and the sample was kept at this temperature for $90 \mathrm{~min}$. The oxidation process was monitored by a Genesys 422 quadrupole mass analyzer (QMS).

FT-IR spectra were obtained using a BRUKER $113 \mathrm{v}$ spectrophotometer $\left(4 \mathrm{~cm}^{-1}\right.$ resolution, MCT detector). WZ-based samples were inspected in the form of thin layer depositions $\left(\sim 10 \mathrm{mg} \mathrm{cm}^{-2}\right)$ on Si wafers, starting from aqueous suspensions. All samples were activated in controlled atmosphere at $300{ }^{\circ} \mathrm{C}$ in a lab-made quartz IR cell, equipped with $\mathrm{KBr}$ windows and characterised by a very small optical path $(2 \mathrm{~mm})$. The cell was connected to a high-vacuum glass line, equipped with mechanical and turbo molecular pumps (capable of a residual pressure $p<10^{-5}$ Torr), which allows to perform strictly in situ adsorption/desorption experiments of molecular probes. The study of surface acidity was performed using as probe 2,6-dimethylpyridine (2,6-DMP). 2,6-DMP was first adsorbed/desorbed at room temperature (RT), and then desorbed at $150{ }^{\circ} \mathrm{C}$.

Temperature programmed reduction (TPR) experiments were carried out in a lab-made apparatus with $5 \% \mathrm{H}_{2} / \mathrm{Ar}$ gas mixture
( $40 \mathrm{ml} / \mathrm{min}$ ). $\mathrm{H}_{2}$ uptake was monitored by a Gow-Mac thermal conductivity detector (TCD). $100 \mathrm{mg}$ of the sample were loaded in a quartz reactor and flushed with a mixture of $\mathrm{H}_{2}(5 \%) / \mathrm{Ar}$ from 25 to $900^{\circ} \mathrm{C}$, with a rate of $10^{\circ} \mathrm{C} / \mathrm{min}$. The reduction process was monitored by TCD and a quadrupole mass spectrometer.

$\mathrm{X}$-ray photoelectron spectra were taken in a M-probe apparatus (Surface Science Instruments). The source was monochromatic AlK radiation $(1486.6 \mathrm{eV})$. A spot size of $200 \times 750 \mathrm{~mm}$ and a pass energy of $20.48 \mathrm{eV}$ were used. The energy scale was calibrated with reference to the $4 \mathrm{f}_{7 / 2}$ level of a freshly evaporated gold sample, at $84.00 \pm 0.1 \mathrm{eV}$, and with reference to the $2 \mathrm{p}_{3 / 2}$ and 3 s levels of copper at $932.47 \pm 0.1$ and $122.39 \pm 0.15 \mathrm{eV}$, respectively. The binding energies (BE) were corrected for specimen charging by referencing the $\mathrm{C} 1 \mathrm{~s}$ peak to $284.6 \mathrm{eV}$, and the background was subtracted using Shirley's method.

\subsection{Catalytic tests}

The liquid-phase acylation reactions were carried out under atmospheric pressure in a $25 \mathrm{~mL}$ thermostated glass batch reactor $[3,5]$. The catalyst $\left(200 \mathrm{mg}\right.$ ) was activated at $450^{\circ} \mathrm{C}$ in flowing air for $1.5 \mathrm{~h}$ and kept dry. The reactor was charged with the internal standard, the substrate (used also as solvent of reaction), the acylating agent and then carried up at the reaction temperature. Then the catalyst was added to the reactor. Aliquots of the reaction mixture were taken periodically after $10,20,30,60,90,120$ and $180 \mathrm{~min}$, and analysed by a gas chromatography system (HPG1540A) equipped with an HP-5 column and a FID detector.

The following reagents and reaction conditions were used:

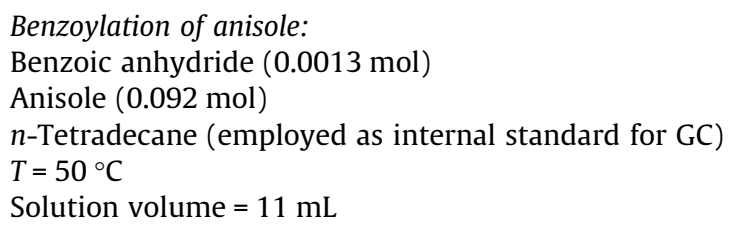

Acylation of veratrole:

Acetic anhydride $(0.078 \mathrm{~mol})$

Veratrole $(0.0078 \mathrm{~mol})$

$n$-Tetradecane (employed as internal standard for GC)

$T=80^{\circ} \mathrm{C}$

Solution Volume $=11 \mathrm{~mL}$

Since the substrates were in excess, conversion was based on the benzoic or acetic anhydride consumption $\left(\mathrm{C}_{\mathrm{A} 0}-\mathrm{C}_{\mathrm{A}}\right)$ and yield was calculated on the production of 2- and 4-methoxybenzophenone (2- and 4-MPB) and 3,4-dimethoxyacetophenone (3,4-DAP) isomers respectively.

Conversion $(\%)=\frac{C_{\mathrm{A}_{0}}-C_{\mathrm{A}}}{C_{A_{0}}} \times 100$

Yield $(\%)=\frac{C_{M P B}}{C_{A_{0}}} \times 100 \quad$ Yield $(\%)=\frac{C_{D A P}}{C_{A_{0}}} \times 100$

Selectivity $(\%)=\frac{C_{x}}{\sum C_{x}} \times 100_{C x=\text { ortho/para-isomers concentration }}$

The turnover frequencies (TOF) of the catalysts were expressed as the number of moles of anhydride converted per mole of active sites $(A S)$ in the catalysts per seconds $\left(\mathrm{mol} \mathrm{mol}^{-1} \mathrm{~s}^{-1}\right)$. For the $\beta$ zeolite $(\mathrm{Si} / \mathrm{Al}=108)$ the number of active protons was taken to be equivalent to the $\mathrm{Al}$ content [8] and for the WZ catalysts the number of active sites was calculated from the nominal $\mathrm{W}$ loading on $\mathrm{ZrO}_{2}$. 
$\mathrm{TOF}=\frac{\mathrm{Mol}_{\text {Ain }}-\mathrm{Mol}_{\text {Aout }}}{\mathrm{Mol}_{\mathrm{AS}}} \times \mathrm{time}^{-1}$

\section{Results and discussion}

The catalytic activity in liquid phase was studied in the acylation of anisole and veratrole (Scheme 1) under mild reaction conditions. Friedel-Crafts acylation of aromatic compounds is widely used in the synthesis of aromatic ketones, that are important intermediates for the production of pharmaceuticals, dyes, agrochemicals and fragrances. In particular, acylation of anisole and veratrole (1,2-dimethoxy benzene) leads to the synthesis of $p$-acetoanisole and acetoveratrole, precursors of a sun protector (Parsol) and of a component in an insecticide formulation (Verbutin) respectively $[21,22]$. Moreover acetoveratrole is used for the synthesis of papaverine, an opium-alkaloid antispasmodic.

In the mild reaction conditions under study, namely atmospheric pressure and low temperature $\left(50^{\circ} \mathrm{C}\right)$, anisole reacts with benzoic anhydride to give a mixture of 2- and 4-methoxybenzophenone (2- and 4-MPB) with a selectivity greater than $96 \%$ toward the desired product (4-MPB). On the contrary, the veratrole reaction leads only to 3,4-dimethoxy acetophenone as product (3,4-DAP). The only GC-detectable side reaction is the decomposition of benzoic and acetic anhydride with water to give benzoic acid and acetic acid, respectively.

Preliminary experiments showed that the system works in a strictly kinetic regime.

Conversion and yields towards the desired products, after $3 \mathrm{~h}$ of reaction, are reported in Table 1 . As expected, mere $\mathrm{AZ}$ and $\mathrm{WO}_{3}$ samples are catalytically inactive in the acylation reactions. After $24 \mathrm{~h}$ of reactions conversion and yield for both the fresh catalysts and in both the reactions are substantially unchanged. On the other side, AZW sample exhibits in both reactions the best catalytic performances with conversion and yield quite higher than that obtained with the XZW catalyst.

In Fig. 1 it is reported the time effect on benzoic and acetic anhydrides conversions. It is interesting to note that for both the systems and both the investigated reactions the conversion increased continuously with time, despite a progressive decrease in the initial rates can be observed at long reaction times. This partial catalyst deactivation can be attributed to the adsorption of acylation products on the catalyst surface, which blocks the accessibility of the reactants to the active sites. This phenomenon is slightly more prominent for the xerogel sample.

To establish the relation between catalytic activity and active phase $(\mathrm{W})$ the turnover frequencies (TOF, mol mol $\mathrm{W}^{-1} \mathrm{~s}^{-1}$ ) were determined (Table 1). As it can be seen, regardless of the substrate (anisole or veratrole), the aerogel sample is the most active. The experimental data explicitly show that the catalytic activity depends on the $\mathrm{W}$ surface density and that the highest activity corresponds to the lower coverage of $\mathrm{W}$ on the $\mathrm{ZrO}_{2}$ support.

For comparison a $\beta$-zeolite, which is the catalyst habitually used in these reactions, was investigated in the anisole reaction under the same experimental conditions. A conversion of $36 \%$ and a yield of $12 \%$ were obtained for this sample. If we compare the turnover frequencies of the $\beta$-zeolite, calculated as a function of the framework molar fraction of aluminium, with that of the WZ systems, we observe that these last samples are definitely more active. Moreover, for the $\beta$-zeolite a clear deactivation occurred, since it reaches a plateau already after the first $60 \mathrm{~min}$. This deactivation, more prominent than in the WZ samples, can be attributed to the strong adsorption of the acylation product on the catalytic surface. Such strong adsorption is favoured by the microporous channel of the zeolite. In any case, the obtained results show the catalytic ability of both the WZ investigated catalysts.

In an attempt to explain the differences in the catalytic behaviour, the catalysts were characterised by different techniques. It's well-known that the catalytic activity in both acetylation and benzoylation reactions can be owed to (i) the presence of Brønsted acid sites and (ii) on the extent of Brønsted-to-Lewis sites ratio [24,25]. For these reasons, FT-IR spectroscopy measurements have been resorted to in order to evaluate the acidic features of the samples. All systems were inspected in a medium-high dehydration stage, and the total acidity (Brønsted and Lewis) was tested by the adsorption/desorption of 2,6-DMP in the RT- $150{ }^{\circ} \mathrm{C}$ temperature range. In the spectra of both aerogel and xerogel samples (Fig. 2) several components, among which two signals relative to physisorbed and H-bonded 2,6-DMP species ( $\sim 1580$ and $\sim 1590 \mathrm{~cm}^{-1}$, respectively), are present [26,27]. Moreover, two bands located at $\sim 1644$ and $\sim 1627 \mathrm{~cm}^{-1}$ are observed: these signals are ascribable to the $8 \mathrm{a}-$ $8 \mathrm{~b}$ modes of 2,6-dimethylpiridinium ions, that are generated by the interaction of 2,6-DMP with Brønsted acid sites present on the catalysts surface [26,27].

Inspecting in details the curves concerning the contact with the base excess (see the highlighted of spectra evidenced by the dotted line in Fig. 2), a shoulder at $\sim 1602-1604 \mathrm{~cm}^{-1}$ can be observed. This aspect is more evident by evacuation of adsorbed 2,6-DMP at RT, as better resolved (though weak) signals remain at $\sim 1604$ $1606 \mathrm{~cm}^{-1}$ (see the highlighted spectra evidenced by the dotted line in Fig. 2) and, after evacuation at $150^{\circ} \mathrm{C}$, these bands totally disappear. The above mentioned spectral components can be ascribed to the strongest fraction of Lewis-bound 2,6-DMP species interacting with $\mathrm{Zr}^{4+}$ cations [27]. All these experimental data<smiles>COc1ccccc1</smiles>

1. anisole reaction<smiles>COc1ccc(C(C)=O)cc1OC</smiles> 
Table 1

Catalytic performances after $3 \mathrm{~h}$ of reaction.

\begin{tabular}{|c|c|c|c|c|c|c|c|c|}
\hline Sample & Substrate & Anhydride & Conversion (\%) & Yield (\%) & $\begin{array}{l}\text { Selectivity } \\
\text { (4-MPB) }\end{array}$ & $\begin{array}{l}\text { Selectivity } \\
\text { (3,4-DMA) }\end{array}$ & $\begin{array}{l}\text { TOF after } 10 \mathrm{~min} \\
\left(\times 10^{-3} \mathrm{~s}^{-1}\right)\end{array}$ & $\begin{array}{l}\text { TOF after } 180 \mathrm{~min} \\
\left(\times 10^{-3} \mathrm{~s}^{-1}\right)\end{array}$ \\
\hline AZW & Anisole & Benzoic & 61 & 56 & $>96$ & & 5.4 & 0.7 \\
\hline XZW & Anisole & Benzoic & 42 & 38 & $>96$ & & 3.0 & 0.4 \\
\hline $\mathrm{WO}_{3}$ & Anisole & Benzoic & & & & & & \\
\hline $\mathrm{AZ}$ & Anisole & Benzoic & & & & & & \\
\hline AZW & Veratole & Acetic & 79 & 69 & & 100 & 44 & 4.4 \\
\hline XZW & Veratole & Acetic & 69 & 63 & & 100 & 37 & 3.9 \\
\hline $\mathrm{WO}_{3}$ & Veratole & Acetic & 0 & 0 & & & & \\
\hline $\mathrm{AZ}$ & Veratole & Acetic & 0 & 0 & & & & \\
\hline$\beta$-Zeolite & Anisole & Benzoic & 36 & 12 & $>95$ & & 1.7 & 0.2 \\
\hline
\end{tabular}
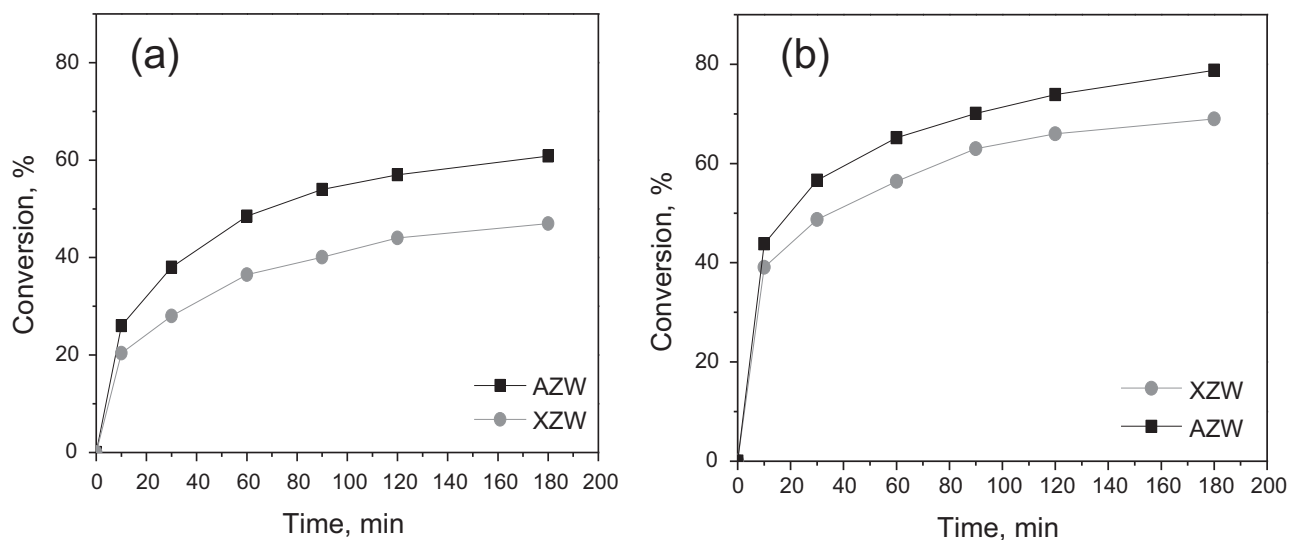

Fig. 1. Effect of time on anhydride conversion; (a) anisole substrate, (b) veratrole substrate.

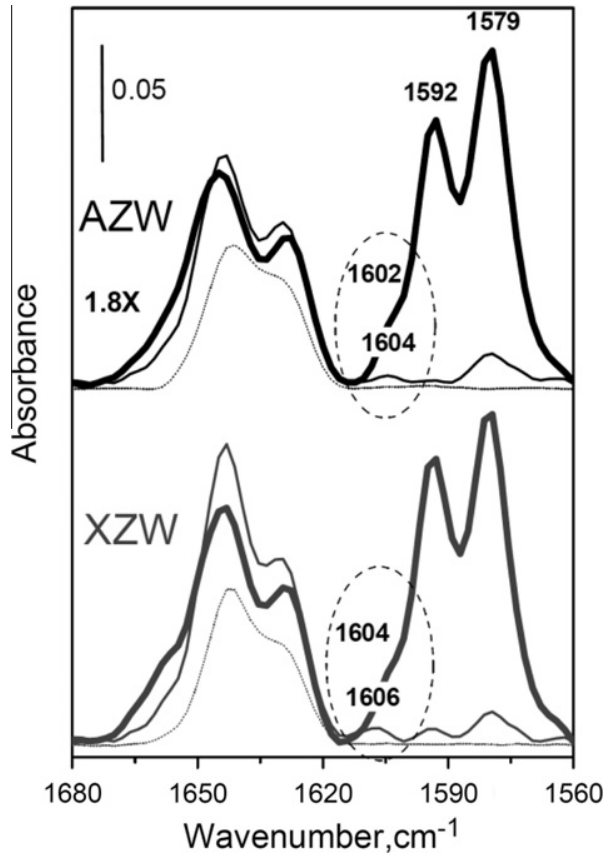

Fig. 2. Differential absorbance spectra, normalised against the background spectrum of the starting sample activated at $400^{\circ} \mathrm{C}$, relative to the adsorption/ desorption of 2,6-DMP on XZW and on AZW, obtained in the vibrational region of 2,6-DMP 8a and 8b modes after contact at RT with the vapour pressure of 2,6-DMP ( $\sim 3$ Torr) (bold curves), after RT evacuation of the 2,6-DMP excess [fine curves] and after outgassing at $150{ }^{\circ} \mathrm{C}$ for 15 min (dotted curves). For a better comparison among spectra of the different systems, spectral set of the AZW catalyst has been ordinate-magnified, as indicated on the curves.

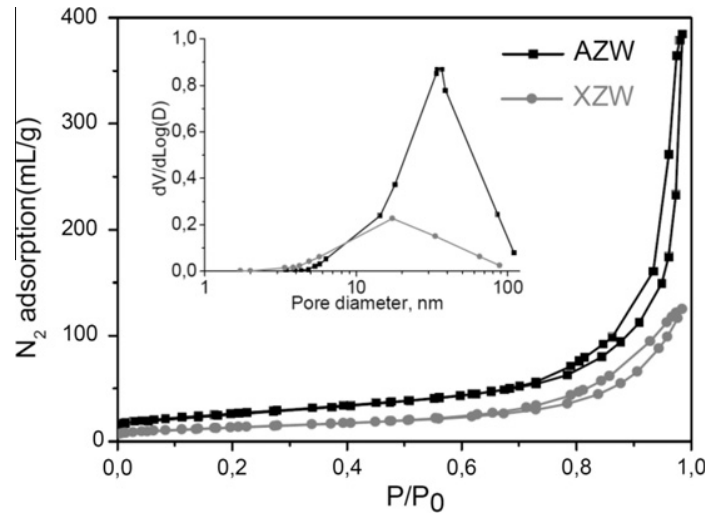

Fig. 3. $\mathrm{N}_{2}$ physisorption isotherms of samples and (inset) their $\mathrm{BHJ}$ pore size distributions.

indicate the presence of both types of acidity (Brønsted and Lewis) in both the investigated samples without significant differences in strength. Therefore, the different behaviour in the acylation reactions cannot be ascribable to surface acidity as such, but it is likely to be correlated with other physico-chemical properties of the catalysts.

So, with the aim of explaining the catalytic performances, a further detailed characterization of the catalysts was performed, taking into account both their textural and red-ox properties.

In Fig. 3 the $\mathrm{N}_{2}$ adsorption-desorption isotherms and the pore size distributions obtained using the $\mathrm{BJH}$ method applied to the isotherm adsorption branch, are shown. All corresponding values 
Table 2

Textural properties of the samples.

\begin{tabular}{lllll}
\hline Samples & $\begin{array}{l}\text { Surface area } \\
\left(\mathrm{m}^{2} / \mathrm{g}\right)\end{array}$ & $\begin{array}{l}\text { Pore diameter } \\
(\mathrm{nm})\end{array}$ & $\begin{array}{l}\text { Pore volume } \\
(\mathrm{mL} / \mathrm{g})\end{array}$ & $\begin{array}{l}\delta \\
\left(\mathrm{N}_{\mathrm{at}} / \mathrm{nm}^{2}\right)\end{array}$ \\
\hline $\mathrm{AZW}$ & 94 & $6-90$ & 0.6 & 3.4 \\
$\mathrm{XZW}$ & 48 & $3-15$ & 0.2 & 6.7 \\
$\mathrm{AZ}$ & 35 & & 0.2 & 0 \\
$\mathrm{WO}_{3}$ & 6 & & 0.05 & 0 \\
\hline
\end{tabular}

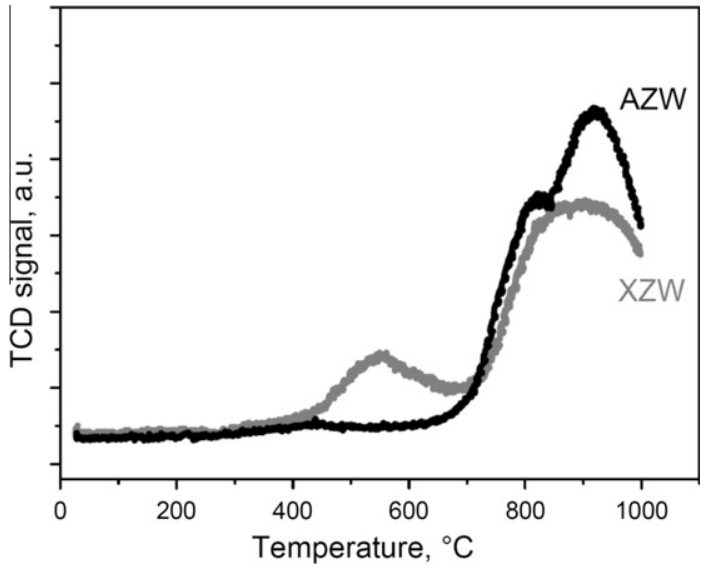

Fig. 4. TPR profiles of catalysts.

Table 3

Elemental composition from XPS analyses.

\begin{tabular}{lllll}
\hline Sample & O1s (\%) & C1s (\%) & W (\%) & Zr3d (\%) \\
\hline AZW & 45 & 31 & 2 & 22 \\
XZW & 50 & 25 & 2 & 23 \\
\hline
\end{tabular}

are reported in Table 2. The isotherms are similar in shape and both the samples exhibit a type IV isotherm, as expected for a mesoporous system. Still, the amount of $\mathrm{N}_{2}$ adsorbed in the case of aerogel is noticeably higher and the capillary condensation is slightly shifted to larger $\mathrm{p} / \mathrm{p}_{0}$ values. The corresponding pore size distributions are unimodal, but the curve of the aerogel sample is broader and shifted toward higher pore diameter values. Data reported in Table 2 show that the BET surface area of both $\mathrm{ZrO}_{2} /$ $\mathrm{WO}_{3}$ catalysts is larger than that of the $\mathrm{AZ}$ sample. This result is in agreement with previous studies [28] showing that the presence of a dopant agent reduces the crystal growth of $\mathrm{ZrO}_{2}$ inhibiting the sintering, with a consequent increase of the surface area. This phenomenon is particularly evident for the aerogel catalyst (AZW), which shows the highest value of surface area. In fact, the removal of a solvent above its critical point occurs with no capillary pressure because there are no liquid-vapour interfaces. Thus in the aerogel formation there is a greatly reduced driving force for shrinkage (very marked in the case of xerogel system) that leads to more porous primary particles that are more stable during the thermal treatment at $800^{\circ} \mathrm{C}$. This results in a low density final material with higher surface area and a unique texture of the porous network. Moreover, it is important to highlight that the surface area of the AZW sample $\left(94 \mathrm{~m}^{2} / \mathrm{g}\right)$ is much higher than that obtained for a $\mathrm{ZrO}_{2}-\mathrm{WO}_{3}$ system with the same $\mathrm{WO}_{3}$ content but synthesized by a wet impregnation method $\left(54 \mathrm{~m}^{2} / \mathrm{g}\right)[15,29]$.

The TPR profiles of the XZW and AZW samples are reported in Fig. 4. According to literature data [30], pure $\mathrm{WO}_{3}$ exhibits three reduction peaks: (i) the first at $540^{\circ} \mathrm{C}\left(\mathrm{WO}_{3} \rightarrow \mathrm{W}_{20} \mathrm{O}_{58}\right)$, (ii) a sharp peak at $775^{\circ} \mathrm{C}\left(\mathrm{W}_{20} \mathrm{O}_{58} \rightarrow \mathrm{WO}_{2}\right)$ and (iii) a last peak at higher temperature $\left(\mathrm{WO}_{2} \rightarrow \mathrm{W}\right)$. In the $25-900{ }^{\circ} \mathrm{C}$ temperature range, the $\mathrm{AZ}$ sample (not reported in Figure) does not show any detectable TPR peak, therefore the signals of the mixed oxides can be ascribable only to the $\mathrm{WO}_{x}$ reduction. The TPR profile of XZW sample shows two peaks at 550 and $897^{\circ} \mathrm{C}$, respectively, while for AZW catalysts a shoulder at $820^{\circ} \mathrm{C}$ and a main band at $920^{\circ} \mathrm{C}$ were detected. For both samples the third reduction band is undetectable in the investigated temperature range. It is possible to observe that, in agreement with previous studies [31,32], the $\mathrm{H}_{2}$ consump-

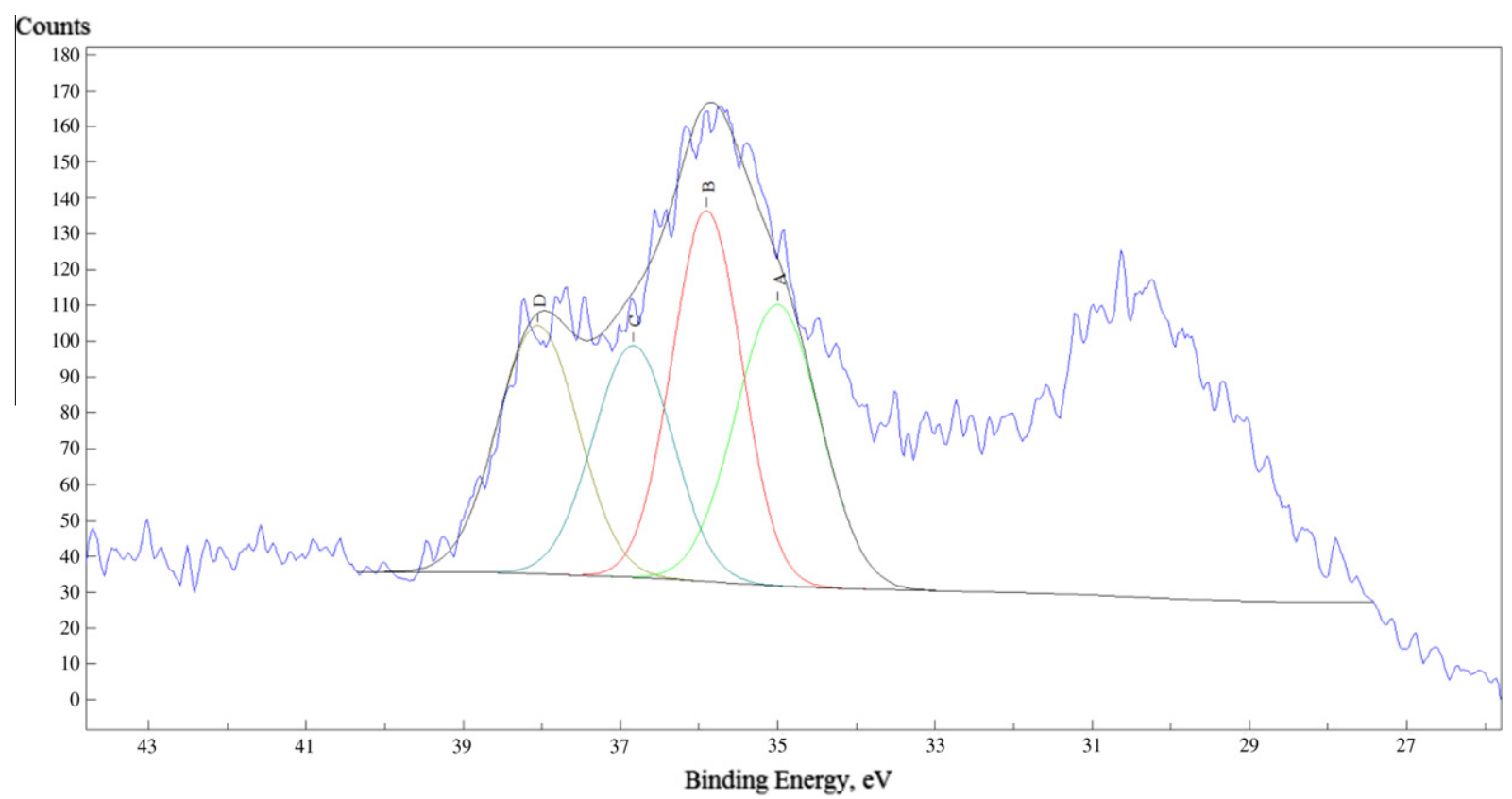

Fig. 5. XPS region partially overlapping $W 4 f, \mathrm{Zr} 4 \mathrm{p}$ and 0 2s peaks. Fitted peaks: $W 4 f_{7 / 2}$ for $W 5+(A)$ and $W 6+(B), W 4 f_{5 / 2}$ for $W 5+(C)$ and $W 6^{6}(D)$. 


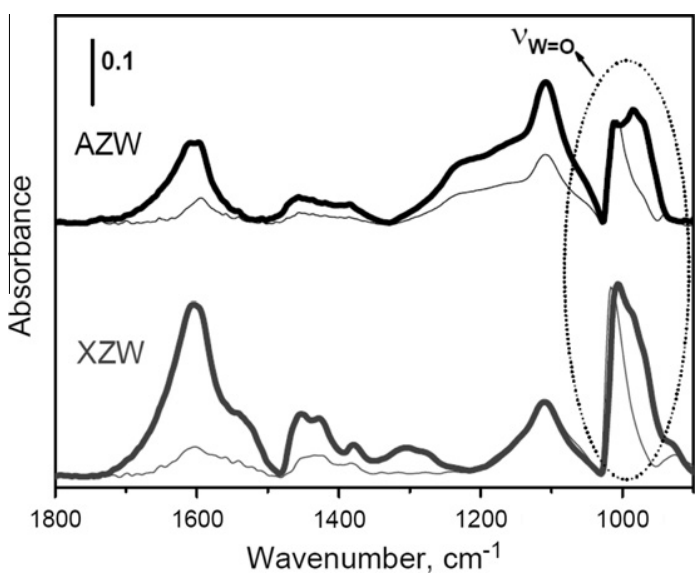

Fig. 6. Absorbance spectra in the $1800-900 \mathrm{~cm}^{-1}$ spectral range of XZW and AZW after evacuation at RT of $30 \mathrm{~min}$ (bold curves) and after activation at $400{ }^{\circ} \mathrm{C}$ in presence of oxygen (fine curves).

tion band shifts toward lower temperature increasing the tungsten surface density $\left(\mathrm{N}_{\mathrm{at}} / \mathrm{nm}^{2}\right.$ : 3.4 for AZW sample; 6.7 for XZW catalyst). As reported by Martinez et al. [32] the large and more interconnetted $\mathrm{WO}_{x}$ clusters formed at increasing tungsten surface density are easier to reduce than smaller and more isolated one prevailing at low surface densities [33].

The presence of different tungstates species on the catalyst surface as results of the difference $\mathrm{W} / \mathrm{Zr}$ surface density was confirmed by XPS analyses (the surface elemental composition are reported in Table 3$)$.

$\mathrm{W}(4 \mathrm{f})$ region is rather complicated due to the partial overlap of W4f peaks ( $>33 \mathrm{eV}), \mathrm{Zr} 4 \mathrm{p}(<31 \mathrm{eV})$ and $\mathrm{O} 2 \mathrm{~s}(>24 \mathrm{eV})$. The W(4f) region of the XPS spectrum for the xerogel sample (XZW, see Fig. 5) can be resolved by two doublets with the $\mathrm{W}\left(4 \mathrm{f}_{7 / 2}\right)$ components at 35.8 and $34.7 \mathrm{eV}$, that can be assigned to $\mathrm{W}^{6+}$ and $\mathrm{W}^{5+}$ species respectively $\left(\mathrm{W}^{6+}\right.$ species $>\mathrm{W}^{5+}$ species) [34]. The XPS profile of the aerogel system (AZW) presents, on the contrary, only a doublet with the $\mathrm{W}\left(4 \mathrm{f}_{7 / 2}\right)$ component located at $35.4 \mathrm{eV}$ ascribable to $\mathrm{W}^{6+}$. In the case of the AZW sample, all the W surface atoms are in the highest oxidation state in the form of crystalline $\mathrm{WO}_{3}$. On the contrary, in the XZW sample the $\mathrm{W}$ atoms are partially reduced and arranged as WOx nanoclusters dispersed on the zirconia surface [35].
The nature of the tungstate species present on the catalysts surface were revealed also by FTIR analyses. The spectra, collected at RT and after activation at $400{ }^{\circ} \mathrm{C}$, are reported in Fig. 6. For both AZW and XZW systems a band at $\sim 1000 \mathrm{~cm}^{-1}$ can be observed: it can be assigned to the symmetrical stretching vibration of $\mathrm{W}=\mathrm{O}$ bonds of octahedrically coordinated species present at the $\mathrm{ZrO}_{2}$ surface [36]. This band is located at higher frequencies after activation at $400{ }^{\circ} \mathrm{C}$ and this shift in its spectral position can be attributed to an increase in the strength of interaction between tungsten and zirconia, most likely due to the dehydration effect connected to the thermal treatment.

As expected, the synthetic method and in particular the way of solvent extraction, results in relevant differences in the physicochemical properties of the final materials, i.e. surface area, pore organisation, metal reducibility, W/Zr surface density and metal interaction.

All these differences can explain the catalytic results. In fact, the best performance exhibited by the aerogel system can be ascribed mainly to the presence of the highest number of active sites on its surface. Brønsted acid sites are formed in the most exposed or well dispersed $\mathrm{W}^{6+}$ atoms [37], and consequently it is possible to assume the existence of a higher Brønsted acid density for the aerogel sample, where all the $\mathrm{W}$ surface atoms are in the highest oxidation state. As a consequence, despite in both the investigated systems the nature and the strength of the acid sites is the same, as demonstrate by FTIR analyses, the aerogel samples possess a higher number of active Brønsted catalytic sites that are responsible of its highest activity in the acylation reactions.

\subsection{Investigation on the recycling test}

With the purpose of recycling the samples, the exhausted catalysts were recovered and reused for three runs. As previously discussed [38,39], the catalysts deactivation in these reactions is likely due to the presence of organic species adsorbed on the surface (indicated by the brown colour assumed by the exhausted catalysts), which are difficult to remove by simply washing with solvents $[40,41]$. Therefore, for all these catalytic systems a regeneration step by thermal treatment in air is required.

After $3 \mathrm{~h}$ of reaction, the catalysts were filtered from the slurry, washed either with anisole or veratrole, dried at $110^{\circ} \mathrm{C}$ overnight and regenerated by thermal treatment in air at $450^{\circ} \mathrm{C}$ for $90 \mathrm{~min}$. Also the $\beta$-zeolite was recovered and regenerated but already in

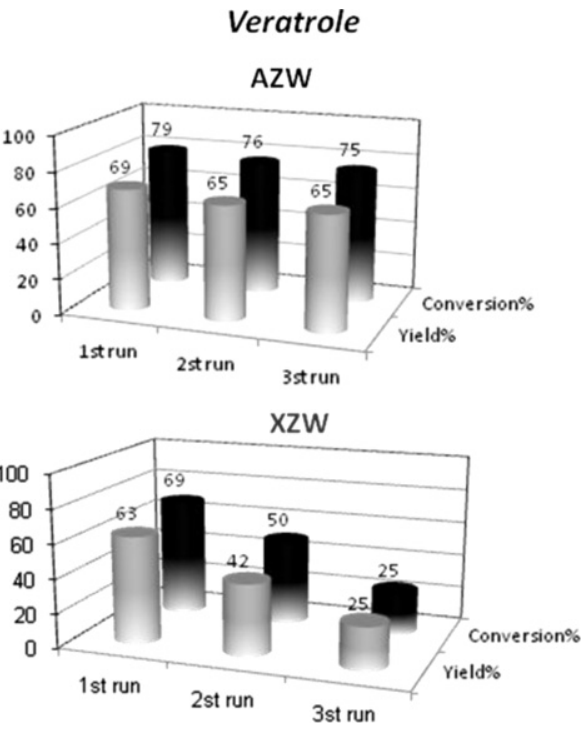

Fig. 7. Comparison of catalytic activity and reuse tests in the acylation of anisole with benzoic anhydride and in the acylation of veratrole with acetic anhydride. 


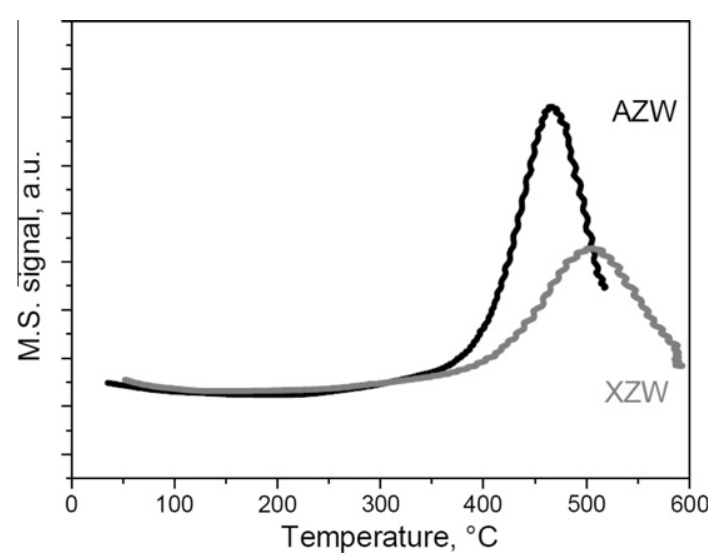

Fig. 8. TPO profiles of the exhausted catalysts after acylation of anisole with benzoic anhydride.

the first reuse it is turned out to be completely inactive. This result was in part expected: the limited thermal stability of the zeolites prevents regeneration by high temperature treatments that could involve the collapse of the crystal lattice. Moreover, the same recovery of the zeolite by filtration is made difficult by the extremely dusty consistency of the same which involves a substantial loss of the initial loaded catalyst.

The results of the recycling tests for the WZ samples are reported in Fig. 7. It is possible to observe interesting differences in the behaviour of the two samples. In the case of AZW system the catalytic activity was restored almost completely after calcination. On the contrary, a considerable decrease in yield was observed yet in the first reuse for XZW catalyst.

In order to study the oxidation profile and the carbonaceous species deposited on the different catalysts, TPO-MS experiments were carried out on the exhausted catalysts. The analysis conditions were very similar to those of the calcination treatment. For all the systems the main product obtained by the oxidation process was $\mathrm{CO}_{2}(\mathrm{~m} / \mathrm{z}=44)$ generated during the combustion of carbonaceous species. As shown in Fig. 8, after the anisole reaction the AZW sample shows an oxidation peak starting at $\sim 350{ }^{\circ} \mathrm{C}$ with a maximum at $447^{\circ} \mathrm{C}$. On the contrary, for what concerns the XZW catalyst, the $\mathrm{CO}_{2}$ evolution starts at higher temperatures $\left(\sim 400{ }^{\circ} \mathrm{C}\right)$. The latter result is probably ascribable to the morphological features of the system, and, in particular, to its pore organization. In fact, the presence of a significant fraction of relatively small pores can favour their faster obstruction and the consequent deposition on the oxide surface of a consistent fraction of organic species [42,43]. Moreover, the fraction of carbonaceous species accumulated inside the smaller pores makes difficult the complete cleaning of the catalyst surface.

These hypotheses are supported by the surface elemental composition obtained by XPS analyses. The fraction of carbon on the aerogel surface is almost the same for the fresh and the exhausted sample. On the contrary, an increase (from 25\% to 28\%) of surface carbon was detected in the used xerogel catalyst.

The supercritical extraction plays a central role in the recycling step, allowing the complete restoration of the catalytic activity of the aerogel sample by calcination at $450{ }^{\circ} \mathrm{C}$, even after three catalytic runs. This is a very promising result and represents a concrete advantage in the use of the aerogel $\mathrm{WO}_{3}-\mathrm{ZrO}_{2}$ systems in comparison to other thermal labile catalysts.

\section{Conclusions}

$\mathrm{WO}_{3} / \mathrm{ZrO}_{2}$ catalysts were synthesized using a reliable sol-gel method. All samples were found to be active in acylation reaction of veratrole and anisole with good conversions and yields despite the mild reaction conditions. The synthetic parameters and, in particular, the solvent extraction step causes some important variations in the physico-chemical features of the investigated systems and in their catalytic activity. The best performance was achieved by the aerogel sample obtained by the supercritical extraction of the solvent that prevents the collapse of the porous network of the wet gel and it allows to obtain expanded structure with unusual porous texture. These more porous primary particles are more stable during high temperature calcination treatment and lead to final materials with higher surface area, different pore organisation and optimal surface density of $\mathrm{W} / \mathrm{Zr}$. The supercritical extraction plays a central role especially in the recycling, allowing the complete restoration of the catalytic activity, by a proper calcination, even after three runs.

\section{Acknowledgement}

We thank Mrs. Tania Fantinel for technical assistance.

\section{References}

[1] J. Cejka, A. Corma, S. Zones, Zeolites and Catalysis, Wiley-VCH, Weinheim, 2010.

[2] G. Sartori, R. Maggi, Chem. Rev. 106 (2006) 1077-1104.

[3] M. Signoretto, A. Torchiaro, A. Breda, F. Pinna, G. Cerrato, C. Morterra, Appl. Catal. B 84 (2008) 363-371.

[4] M. Signoretto, S. Melada, F. Pinna, S. Polizzi, G. Cerrato, C. Morterra, Microporous Mesoporous Mater. 81 (2005) 19-29.

[5] E. Ghedini, M. Signoretto, F. Pinna, G. Cerrato, C. Morterra, Appl. Catal. B 67 (2006) 24-33.

[6] B.M. Reddy, P.M. Sreekanth, V.R. Reddy, J. Mol. Catal A: Chem. 225 (2005) 7178.

[7] A. Bordoloi, N.T. Mathew, B.M. Devassy, S.P. Mirajkar, S.B. Halligudi, J. Mol. Catal. A: Chem. 247 (2006) 58-64.

[8] B. Devassy, S.B. Halligudi, J. Catal. 236 (2005) 313-323.

[9] Y.-M. Park, D.W. Lee, D.-K. Kim, J.-S. Lee, K.-Y. Lee, Catal. Today 131 (2008) 238-243.

[10] G. Sunita, B.M. Devassy, A. Vinu, D.P. Sawant, V.V. Balasubramanian, S.B. Halligudi, Catal. Comm. 9 (2008) 696-702.

[11] G. Larsen, E. Lotero, R.D. Parra, L.M. Petkovic, H.S. Silva, S. Raghavan, Appl Catal. A 130 (1995) 213-226.

[12] S. Sarish, B.M. Devassy, S.B. Halligudi, J. Mol. Catal. A: Chem. 235 (2005) 44-51.

[13] G.H. Chuah, Catal. Today 49 (1999) 131-139.

[14] K.M. Parida, P.K. Pattnayak, P. Mohapatra, J. Mol. Catal. A: Chem. 260 (2006) 35-42.

[15] M. Signoretto, M. Scarpa, F. Pinna, G. Strukul, P. Canton, A. Benedetti, J. NonCryst. Solids 225 (1998) 178-183.

[16] W. Sun, L. Xu, Y. Chu, W. Shi, J. Colloid Interface Sci. 266 (2003) 99-106.

[17] D.P. Debecker, R. Delaigle, K. Bouchmella, P. Eloy, E.M. Gaigneaux, P. Hubert, Catal. Today 157 (2010) 125-130.

[18] F. Adam, A.I. Mutin, Chem. Eng. J. 171 (2011) 1379-1386.

[19] R.A. Boyse, E.I. Ko, J. Catal. 171 (1997) 191-207.

[20] A. Sarkar, S. Pramanik, A. Achariya, P. Pramanik, Microporous Mesoporous Mater. 115 (2008) 426-431.

[21] M. Guidotti, C. Canaff, J.M. Coustard, P. Magnoux, M. Guisnet, J. Catal. 230 (2005) 384-397.

[22] G.D. Yadav, H.G. Manyar, Microporous Mesoporous Mater. 63 (2003) 85-96.

[23] S. Brunauer, P.H. Emmett, E. Teller, J. Am. Chem. Soc. 60 (1938) 309-315.

[24] R. Sakthivel, H. Prescott, E. Kemnitz, J. Mol. Catal. A: Chem. 223 (2004) 137142.

[25] V. Quaschning, J. Deutsch, P. Druska, H.-J. Niclas, E. Kemnitz, J. Catal. 177 (1998) 164-174.

[26] (a) C. Morterra, G. Cerrato, G. Meligrana, Langmuir 17 (2001) 7053-7060; (b) C. Morterra, G. Meligrana, G. Cerrato, V. Solinas, E. Rombi, M.F. Sini, Langmuir 19 (2003) 5344-5356.

[27] M.A. Cortés-Jácome, C. Nengeles-Chavez, E. López-Salinas, J. Navarrete, T. Torillo, J.A. Toledo, Appl. Catal. A: Gen. 318 (2007) 178-189.

[28] B. Zhao, X. Xu, H. Ma, D. Sun, J. Gao, Catal. Lett. 45 (1997) 237-244.

[29] C. Morterra, G. Cerrato, F. Pinna, M. Signoretto, G. Strukul, J. Catal. 149 (1994) $181-188$.

[30] D.C. Vermaire, P.C. van Berge, J. Catal. 116 (1989) 309-317.

[31] D.G. Barton, S.L. Soled, G.D. Meitzner, G.A. Fuentes, E. Iglesia, J. Catal. 181 (1999) 57-72.

[32] A. Martinez, G. Prieto, M.A. Arribas, P. Concemption, J.F. Sanchez-Royo, J. Catal. 248 (2007) 288-302.

[33] S. Kuba, P.C. Heydorn, R.K. Grasselli, B.C. Gates, M. Che, H. Knozinger, Phys. Chem. Chem. Phys. 3 (2001) 146-154. 
[34] J.F. Moulder, W.F. Stickle, K.D. Bomben, Handbook of X-ray Photoelectron Spectroscopy, Perkin Elmer, Eden Praire, 1992.

[35] D. Di Gregorio, V. Keller, J. Catal. 225 (2004) 45-55.

[36] C.D. Baertsch, S.L. Soled, E. Iglesia, J. Phys. Chem. B 105 (2001) 1320-1330.

[37] M. Scheithauer, R.K. Grasselli, H. Knözinger, Langmuir 14 (1998) 3019-3029.

[38] A. Breda, M. Signoretto, E. Ghedini, F. Pinna, G. Cruciani, Appl. Catal. A 308 (2006) 216-222.

[39] E. Ghedini, M. Signoretto, F. Pinna, G. Cruciani, Catal. Lett. 125 (2008) 359-370

[40] B. Bachiller-Baeza, J.A. Anderson, J. Catal. 228 (2004) 225-233.
[41] F. Zane, S. Melada, M. Signoretto, F. Pinna, Appl. Catal. A: Gen. 299 (2006) 137144.

[42] G. Guignard, V. Pédron, F. Richard, R. Jacquot, M. Spagnol, J.M. Coustard, G. Pérot, Appl. Catal. A: Gen. 234 (2002) 79-90.

[43] (a) J.A. Moulijin, A.E. Van Diepen, F. Kapteijn, in: G. Ertl, H. Knözinger, F. Schüt J. Weitkamp (Eds.), Handbook of Heterogeneous Catalysis, Wiley-VCH, Winheim, 2008, pp. 1-18. chapter 7.1;

(b) J.A. Moulijin, A.E. Van Diepen, F. Kapteijn, Appl. Catal. A: Gen. 212 (2001) 3-16. 